\title{
Em busca da cabeça perdida: memória e sexualidade em Gonzaga Duque
}

\author{
Gilberto Araújo
}

\begin{abstract}
RESUMO: Mais conhecido como crítico de arte, Gonzaga Duque ainda não mereceu o necessário reconhecimento por sua obra de ficção, composta pelo romance Mocidade morta (1899) e pela coletânea de formas breves Horto de mágoas (1914). É a este último título que o presente ensaio se dedica, examinando, com maior detalhe, a narrativa "Agonia por semelhança", em que se pretendem avaliar as conexões simbólicas entre memória e sexualidade, bem como a originalidade estética das técnicas adotadas, com inovadora incursão pelo inconsciente, capaz de antecipar conceitos posteriormente desenvolvidos por Sigmund Freud, como o complexo de Édipo.
\end{abstract}

PALAVRAS-CHAVE: Literatura Brasileira, Simbolismo-Decadentismo, Gonzaga Duque, memória, sexualidade.

\begin{abstract}
Known as an art critic, Gonzaga Duque still did not deserve the necessary recognition for his fictional production, composed by the novel Mocidade morta (1899) and by the collection of short stories Horto de mágoas (1914). It is to this last title that the present essay is dedicated, examining, in greater detail, the narrative "Agonia por semelhança", in which we intend to evaluate the symbolic connections between memory and sexuality, as well as the aesthetic originality of the adopted techniques, with innovative incursion into the unconscious, able to anticipate concepts later developed by Sigmund Freud, such as the Oedipus complex.
\end{abstract}

KEYWORDS: Brazilian Literature, Symbolism-Decadentism, Gonzaga Duque, memory, sexuality. 
$\mathrm{Na}$ esteira dos manuais de boa conduta para moças e senhoras de família, verdadeira moda entre a burguesia da belle époque, Sylvino Junior lançou em 1894 A dona de casa, com subtítulo autoexplicativo: "a mais útil publicação em português contendo guia de higiene privada e conselhos, higiene de alimentação e do vestuário, princípios de economia doméstica, higiene das crianças e da meninice, prejuízos a corrigir, etc.". Salta aos olhos a ênfase na higiene, sob cujos princípios a matriarca deveria se guiar, seja zelando diariamente pela privada ${ }^{2}$ ou contratando amas de leite para a prole, função com requisitos obrigatórios: além de não sofrerem "moléstias nervosas", as mulheres precisariam "ter os seios bem conformados - quer dizer - suficientemente desenvolvidos, sem cicatrizes, cheios, duros, bem veiosos e com os bicos direitos e grossos. $\mathrm{O}$ leite não deve ser branco". ${ }^{3}$

A importância conferida à limpeza da casa e ao corpo feminino deriva do projeto higienista em voga no final do século xix. Em Ordem médica e norma familiar, Jurandir Freire $\operatorname{Costa}^{4}$ informa que, com a urbanização verificada no período, se franquearam à mulher mais possibilidades de abandonar o espaço doméstico e circular na rua. $\mathrm{O}$ higienismo desenvolveu, então, estratégias para devolver as egressas ao lar e assim controlar sua sexualidade. Rivalizando a mãe de família com mundanas e prostitutas, um dos principais mecanismos de domesticação feminina consistiu na excessiva campanha de aleitamento, naturalizado como forma de manter a lactante em casa, sob vigilância do marido ou do médico. O objetivo regulatório torna-se mais evidente quando um componente básico da sexualidade, o prazer, é transferido do corpo do cônjuge para o do filho, a quem, oferecendo o seio, a senhora não sentiria nenhuma dor, apenas gozo. Prova disso é a tese Breves considerações sobre as vantagens do aleitamento materno, defendida por Zeferino Justino da Silva Meirelles, na Faculdade de Medicina do Rio de Janeiro em 1847:

Não é tão somente uma ação especial da vida para a formação do leite, é preciso um estímulo para que entretenha sua secreção e excreção: [...] A criança favorece esta disposição por excitamentos proporcionados à sensibilidade da parte: por instinto ou por

1. JUnIOR, Sylvino. A dona de casa. Rio de Janeiro: Domingos de Magalhães - Editor; Livraria Moderna,

1894, p. 3 .

2. Idem, p. 25.

3. Idem, p. 220.

4. costa, Jurandir Freire. Ordem médica e norma familiar. 2 ed. Rio de Janeiro: Edições Graal, 1983, p. 259. 
acaso, e logo por experiência, ela excita as mamas com a cabeça e com as mãozinhas e estas ligeiras excitações, muitas vezes voluptuosas, determinam um orgasmo particular muito favorável a entreter a função do aleitamento. Estas excitações tanta influência têm sobre a secreção do leite, que amas há que não podem aleitar esta ou aquela criança por não causarem nelas este prurido voluptuoso. [...] A natureza, previdente, teve a sabedoria de colocar o prazer, onde o exercício de uma função é indispensável à vida e a dor quando suas leis são desprezadas. A mãe que cria sente correr com delícia o leite através dos canais que o devem levar à boca de seu filho; como no ato da reprodução ela tem muitas vezes eretismo, voluptuosidade: basta somente que ele lhe estenda os tenros bracinhos para que os seus seios se ingurgitem e que o leite seja ejaculado com força. ${ }^{5}$

Sem a sofisticação teórica do complexo de Épido freudiano, a tese desloca para a amamentação vários componentes do ato sexual, culminado na excreção do leite em explosão orgástica. Não espanta que essas ideias higienistas permeassem a ficção naturalista, produzida algumas décadas depois do estudo de Zeferino Meirelles. No entanto, a publicação da tese na década de 1840, encravada no apogeu da literatura romântica (Gonçalves Dias lançara Primeiros cantos em 1846), realça o intercâmbio, velado ou explícito, entre higienismo e sistemas estéticos em princípio dele distantes ou a ele antagônicos, como o Romantismo, supostamente ancorado em valores como pureza, amor eterno, castidade etc. Se os comportamentos sexuais, sobretudo os polêmicos, interessavam aos naturalistas, o alardeado nefelibatismo de simbolistas e decadentistas é, com bastante frequência, esvaziado de sua seiva material em prol de almas e mistérios. A obra de Cruz e Sousa, pródiga de textos de alta voltagem erótica, é suficiente para desmentir o equívoco, mas o quadro se agrava quando se examina a prosa do período.

Geralmente tachada de rebarbativa e empolada, essa ficção costuma (não) ser lida como coleção de enredos mal ajambrados em mãos de narradores seduzidos pela orgia do significante, sem que se vislumbre nesse aparente desacerto indício cabal de modernidade. Curiosamente, seus autores, se não esquecidos, são destacados pela atuação cultural, fundando órgãos e revistas, porém suas obras permanecem intocadas. São os casos de, entre outros, Colatino Barroso, Lima Campos e Gonzaga Duque, este último nosso objeto, pois nele detectamos acoplamento surpreendente entre memória e sexualidade.

5. Apud costA, op. cit., pp. 263-4, grifos do autor. 
Mais conhecido como crítico de artes plásticas, terreno em que foi pioneiro, ou pelo romance Mocidade morta (1899), Gonzaga Duque semeou nos contos de Horto de mágoas (1914), publicados postumamente, pulsões humanas que só alcançariam semelhante relevo na literatura brasileira a partir de 1920, com Medeiros e Albuquerque e outros, após a divulgação mais sistemática dos estudos de Sigmund Freud. Um exemplo de inovação em Duque concerne ao debate sobre a libido imemorial entre mãe e filho. Evidentemente, os discípulos de Zola já haviam abordado o incesto - é ler Hortência (1888), de Marques de Carvalho -, porém o enfoque de Gonzaga não é rastrear os desdobramentos sociais e morais da relação proibida. Seu ângulo de abordagem tende ao sociopsicanalítico, na medida em que privilegia o contato edipiano com a mãe, elo irrecuperável pela memória consciente, com a qual os personagens entram em conflito. Em direção semelhante, Cruz e Sousa nos deixara, em Evocações (1898), o poema em prosa "Mater", referente ao nascimento de um de seus filhos. A cena do parto, no Dante Negro, surpreende não apenas por focalizar a vagina sanguinolenta da parturiente, crueza a princípio inesperada em autor simbolista, mas também por, lentamente, confundir as figuras de pai e filho, bem como de esposa e mãe, criando imbricada simetria bastante similar à descrita no complexo de Édipo. Coincidentemente, essa abertura para o inconsciente acaba, conforme demonstraremos, dialogando com alguns preceitos higienistas associadas à índole materna, sobremaneira ao revelarmos que o Sylvino Júnior, signatário do manual antes mencionado, é ninguém menos que o próprio Gonzaga Duque, travestido em pseudônimo de estilo objetivo e direto, distinto de sua prosa usualmente caudalosa.

Vera Lins, especialista no autor carioca, ratifica que Horto de mágoas recorre à visualidade no esforço de concretizar, via memória, experiências perdidas. Para ela, a obra do escritor "é sempre um olhar que passa pela memória, pela imaginação, é sempre procura nostálgica de alguma situação já vivida e apenas lembrada”. ${ }^{6}$ Com efeito, vários contos corroboram tal assertiva, a exemplo de "Benditos olhos!", cujo protagonista desenvolve fixação pelo olhar verde de uma mulher quase desconhecida, a ponto de persegui-la até a morte, quando, perante seu féretro, entrevê manchas esverdeadas na defunta, e a pálpebra do observador assume a mesma coloração, fechando o circuito obsessivo.

6. LINS, Vera. "De achados e perdidos". In: DuQue, Gonzaga. Horto de mágoas. 2 ed. Rio de Janeiro: Secretaria Municipal de Cultural, 1996, p. 12. 
Advindo do Romantismo e presente em Álvares de Azevedo (cf. “Solfieri”) e José de Alencar (cf. A pata da gazela), o topos da procura da amada desconhecida é levado ao extremo em "Agonia por semelhança". Ao longo do conto, Paulo se esforça para recompor a imagem de uma mulher ideal, despertada pela visão de um lenço negro, depositado em seu quarto branco. Depois de vislumbrar no passado duas figuras capazes de preencher o arquétipo feminino, o homem chega, estupefato, à imagem da mãe, instaurando conflito ainda maior no desfecho da narrativa. Começamos pela abertura:

Paulo fechou sobre os dedos a brochura verde do Panteu, cansado do esoterismo sutil de Peladan, espreguiçou-se, bocejando, no recosto da otomana, e, na calma clara desta hora espraiada do meio-dia, entre paredes nuas de um quarto forrado a novo, duma simplicidade distinta de recém-aboletado, fitou por acaso a mancha a dois tons de um lenço de seda negra, esquecido sobre o mármore cinzento do toucador.

À luz igual, coada pelos stores cremes, a negrura azulenta do lenço feria um contraste imagético de corvo morto na riqueza viva da porcelana rósea do serviço, e parecia um bizarrismo de esgotado em busca de impressionabilidades chocantes e imprevistas o singular despojo do tiro feito pela manhã no asseio daquele móvel de quarto, intacto de uso pela tonalidade branda da ceragem moderna do severo carvalho, cujo tampo resplandecia o cuidadoso polimento das manufaturas a capricho. ${ }^{7}$

No primeiro parágrafo, a monotonia cromática do quarto, resvalando entre branco, preto e cinza, espelha o spleen de Paulo, que, no esplendor da idade balzaquiana, se revela entediado por causa ignota - a aludida "agonia" do título -, bocejando como vários narcotizados fin-de-siècle. Se a brancura excessiva do espaço acompanha o vazio interior do personagem, por outro lado ofusca qualquer conotação positiva ou esclarecedora eventualmente suscitada pela "calma clara desta hora espraiada do meio-dia", registrada em assonância expansiva de /a/, ou pelo conforto luxuoso da habitação. Tudo é novo e limpo, mas a assepsia soa clandestina, provisória, qual o lenço negro. Na simbologia das cores, o verde da brochura perde possível conotação esperançosa, quando Paulo a abandona; importa destacar que a fadiga do rapaz não é motivada pela leitura extensa ou pelo desconforto do cômodo: "recém-aboletado", dispondo de luz satisfatória e de

7. DUQue, Gonzaga. Horto de mágoas. Rio de Janeiro: Benjamin de Aguila - Editor, 1914, p. 25. Optamos pela atualização ortográfica nas citações. 
móvel adequado à atividade, mesmo assim abdica da empreitada, indiciando haver causa anterior e desconhecida para essa saturação.

A dinâmica cromática amplia-se no segundo parágrafo, quando o lenço ganha "negrura azulenta", e o branco da porcelana, tons róseos, tudo agora filtrado pela persiana creme. Os ligeiros acréscimos estendem a paleta e, sub-repticiamente, incitam Paulo à percepção prismática da realidade, multiplicando a quase monocromia anterior em matizes menos cartesianos. Convocando postura participativa e (auto)analítica do sujeito, o espectro de entretons deflagra, portanto, a aventura reflexiva a que doravante o conto se lança. Bem a propósito, o asseio excessivo do quarto está condicionado à expurgação interior, como se Paulo mantivesse purificado fora aquilo que, dentro, nunca será de todo imaculado.

É de fato o conluio entre essência e cenário que detona a cadeia rememorativa: "E quando se fundiram as duas errantes nebulosidades - a ressalta da objetividade do lenço negro, a expelida pela subjetividade do seu espírito agônico -, uma forma se condensou na fusão extrema". ${ }^{8}$ Desse modo, a concepção de memória em Gonzaga Duque não contempla apenas o resgate de experiências vividas; trata-se, na verdade, da intersecção entre elementos da realidade factual (no caso, o lenço) e as inclinações do sujeito. Portanto, as lembranças derivariam de domínio duplo, podendo assim ser perpetuamente ressignificadas, conforme as demandas de dentro ou de fora, âmbitos não raro interligados pelo concurso da imaginação. Caleidoscópica, a memória configura-se, nas palavras do próprio escritor, "infinitamente" 9 , aproximando-se do entendimento de Walter Benjamin, ao declarar que "um acontecimento vivido é finito, ou pelo menos encerrado na esfera do vivido, ao passo que o acontecimento lembrado é sem limites, porque é apenas uma chave para tudo o que veio antes e depois". ${ }^{\circ}$

Com efeito, a atividade reminiscente em "Agonia por semelhança", a julgar pelo próprio título, se é ancorada no pretérito, pretende-se extensiva ao presente, já que revelará a Paulo verdadeiro conteúdo ignorado: a paixão pela mãe. Ilimitado, o empenho recordativo, flagrado em imagens de cansaço e esgotamento, devolverá ao protagonista vários indícios daquilo por que ele batalha mas que, ironicamente, denega. Como todas

\footnotetext{
8. Idem, p. 26.

9. Idem, p. 30.

10. Benjamin, Walter. "A imagem de Proust”. In: Magia e técnica, arte e política: ensaios sobre literatura e história da cultura. 7 ed. Tradução de Sergio Paulo Rouanet. São Paulo. Editora Brasiliense, 1994, p. 37.
} 
as mulheres dão na mãe, Paulo passa a ter diferentes visões femininas que, paulatinamente, lhe vão desenhando o original perdido, trajetória de aparições aqui examinada.

A claridade da sequência inicial não se projeta apenas no espaço. A primeira imagem feminina surge envolta na mesma tonalidade: "Um dia em Berlim... uma saxônia amorosa... Aventuras de rapaz..." ${ }^{11}$ Brotada de mente com "psicopatia escandinava"12, a moça europeia acusa muito mais do que a repetida sedução finissecular pelo Velho Mundo; a rigor, distanciar a proveniência da amante, alocando-a em terreno frio e nebuloso, aguça o enigma da aparição, tão ausente na memória de Paulo quanto a geografia longínqua. Temperando a atmosfera boreal, a "forma rubenesca de mulher veripotente"13 evoca o pintor barroco flamengo Rubens, reconhecido pelos corpos opulentos e volumosos, pródigos de luz em geral contrastada com fundos escuros. Ao debuxar a saxônica, Gonzaga Duque reincide na paleta (quarto claro $x$ lenço escuro) e na sensualização dos contornos. "Sadia da idade produtiva", "alvores lácteos em cristais palidamente sanguíneos", "trevores caliginosos de olhos incendidos" ${ }^{14}$ são alguns designativos dessa mulher, apreendida a partir do baixo ventre, em privilegiada perspectiva erógena: "flexibilidade angular do suporte abdominal aberto em bifurcação esquemática de um caule afrodisíaco e fecundo", "rígido delineamento das coxas", "túmida de tendões, dura de músculas" ${ }^{15}$, "repletos quadris, larga baça de fecundadora", "fartura abaulada e orgulhosa de um ventre frutificador"16, "mulher carnuda", "robustez pagã para a multiplicação da raça dos fortes e dos musculosos", "ancas rígidas", "sólidas plantas" ${ }^{17}$. Para as zonas baixas do corpo, abundam referências artísticas e biológicas de regiões vizinhas aos Países Baixos, aí residindo a "apoteose épica da carnalidade das mulheraças robustas d'Anvers e da Flandres". ${ }^{18}$

Aparentemente, a jovem alemã nada prefigura do "casto" vulto materno ao fim do conto. Contudo, é inusitada a discrepância entre, de um lado, a pletora de signos associados à fertilidade e, doutro, o despojamento de um affair de juventude, mais

\footnotetext{
11. DUQUe, Gonzaga. Op. cit., p. 28.

12. Idem, p. 26.

13. Idem, p. 28.

14. Ibidem.

15. Idem, p. 27.

16. Idem, p. 29.

17. Idem, p. 30.

18. Idem, p. 27.
} 
afeito ao prazer do que à procriação. O vínculo entre erotismo e fecundidade antecipa a sexualização edipiana, também pincelada pela brancura excedente, remissiva tanto ao fluido seminal quanto ao leite materno, o que, em certa medida, dialoga com o discurso higienista antes sumarizado. Nesse aspecto, Paulo amava na substituta europeia a mãe perdida.

O segundo espectro feminino a desfilar no conto reforça o liame entre desejo e família. Senão, vejamos. Após a frustração e o cansaço recordativo, Paulo abandona o livro de Péladan e a otomana, expressando gestualmente sua inquietude, bem como a impertinência da brochura como via de acesso ao ente perseguido. Encontra-se agora "sozinho, estatelado na cama". ${ }^{19}$ Novamente defrontado consigo, o rapaz, embora mais fadigado, recosta em móvel favorável ao descanso e, sobretudo, à atividade erótica, antes minimizada pela silhueta intelectual da cadeira de leitura. $\mathrm{O}$ antigo tédio se converte em excitação e espanto. A cena precedente passava-se ao meio-dia; esta, pela manhã, delineando a trajetória regressiva do evento. Paralelamente, se a germânica remetia à juventude, esta segunda remonta à adolescência, aos "sacolejos da virilidade apontada". ${ }^{\circ}$ Quanto mais Paulo recua - do meio-dia à manhã, da otomana à cama, da idade adulta à puberdade -, mais encontra a família, fato comprovado pela nova visão lembrar-lhe uma tia, "diante de quem passava horas a notar, a namorar, silencioso, numa idolatria de desejos, a beleza radiosa de flor aberta donde se exalava o aroma sensual do Pecado". ${ }^{21}$ Ao abandonar a poltrona do gabinete e o livro e entregar-se à cama, o rapaz é progressivamente devolvido à sua genealogia.

Ao contrário da lubricidade da alemã, da tia privilegiam-se os membros superiores: cabeça, pescoço, colo, ombros, braço, cotovelo, antebraço, mãos. A permissividade algo libertina do primeiro adulto mitiga-se no adolescente, que desenvolve com a familiar erotismo leve e consentido, sem a presença de interditos expressivos, porém mediado por zonas menos acaloradas do corpo feminino. Inclusive, a parente fá-lo recordar "enormes lustres resplandecentes dos salões de luxo" ${ }^{22}$, recinto da convivência social, dessemelhante da remota babilônia do Velho Mundo. Em todo caso, o "busto farto de mulher" ${ }^{23}$ da tia redireciona Paulo ao seio materno.

\footnotetext{
19. Idem, pp. 31-32.

2o. Idem, p. 33 .

21. Ibidem.

22. Idem, p. 32.

23. Ibidem.
} 
Talvez pela culpa então instilada, a alvura pregressa começa a ser borrada de preto: "Era-lhe como um lótus negro esse busto [da tia] vestido na mesma seda preta, realçando o pescoço branco". ${ }^{24}$ Intermediária entre a branca femme fatale e a mãe depois retratada em traços carregados e escuros, a tia sintetiza os componentes cromáticos da cena primitiva: quarto claro e lenço negro unem-se nela para conduzir o sobrinho à epifania derradeira. Inclusive, a irmã da mãe restitui-o à paisagem mais tropical, acordando nele sensações de "tempestades formadas, laivando em jalde, os horizontes de acasos verânicos ou vascas fosforecentes de calmaria". ${ }^{25}$ Por isso, o episódio termina em escuridão - "vasa de Asfaltite", "betume" ${ }^{26}$-, prenúncio dos embargos consagrados no desfecho.

Antes, porém, de alcançar o semblante materno, chega a Paulo "a visão de uma cabeça colorida, largo rosto de matrona a fazer-se, olhos insidiosos sob impulsos púberes de idade primaveral e neve sagrada de avó na cabeleira lançada para o alto, em apanho cuidado de grampos de outro, com requintes moços de conquistas premeditadas". ${ }^{27}$ Em respeito à lógica desenvolvida na narrativa, quanto mais se encaminha à cabeça da consorte fugidia, menos eróticas se afiguram as reminiscências: se o quadril recompôs a alemã, e o busto, a tia, era previsível que a cabeça coroasse a almejada mãe. Todavia, esta parte do corpo é retratada ambiguamente, reunindo marcas da volúpia detectadas nas aparições pretéritas, posta em contraste severo com a imagem santificada da avó, cujos cabelos, conquanto ordenados e claros, escondem "conquistas premeditadas". Ladeiam-se, quase esquizofrenicamente, baixa sexualidade e sublimação da matéria, gerando tecido mal alinhavado, corpo desmembrado de uma Frankenstein feminina. Se é longa a distância espacial, afetiva e genética entre a saxônica e a tia, entre esta e a mãe, o caminho é curto. Sendo a matriarca ao mesmo tempo procurada e rechaçada (pois ativa o remorso culposo no filho), Paulo a lança em fosso inacessível da memória: partindo da tia direto para a avó, preserva a genitora em limbo obscuro, mas não por isso desconfortável. Saiu do busto à cabeça, denegando a face.

Contudo, o sintoma retorna de forma intensa e dolorosa. Na impossibilidade de localizar em si o contorno faltante, o mancebo recorre novamente ao exterior

\footnotetext{
24. Idem, p. 33.

25. Ibidem.

26. Ibidem.

27. Idem, p. 34 .
} 
para suprir a carência afetiva. Tal o lenço do início, uma fotografia, significativamente escondida em maço de cartas íntimas, agora lhe revela a mãe estampada num "cartão carbonado e fino das oficinas de Nadar, onde se manchava a brancura serena de uma velhice nobre". ${ }^{28}$

Não convém aqui pormenorizar os desdobramentos técnicos do surgimento da fotografia no século XIx, bastando mencionar, com Edmond Couchot, que ela ofereceu ao espectador "aquele instante originário em que se encontram reunidos, copresentes num mesmo lugar o sujeito, o objeto e a imagem (latente), de uma maneira quase totalmente automática". ${ }^{29}$ É justo a rapidez propiciada pela técnica que permitirá sua reprodutibilidade, distinguindo-se assim da pintura, que, além de demandar maior tempo para conclusão da obra, caracterizava-se, à época, como universo artesanal, de peças únicas. Na fotografia, o original praticamente nasce para ser reproduzido.

Ora, essa peculiaridade técnica replica, com maestria, a experiência vivida por Paulo em "Agonia por semelhança": entre várias mulheres imaginadas ou retratadas, ele busca uma, imaterializável malgrado a variedade dos suportes. A sequência reprodutória das imagens dilui a existência do original, tornando inviável resgatar a mãe verdadeira. Nesse aspecto, ganha relevância a arte de Félix Nadar, fotógrafo reconhecido por clicar nomes famosos da França oitocentista, a exemplo de Charles Baudelaire, Jules Verne, Victor Hugo e outros. O estilo de flagrar a pessoa em primeiro plano escuro projetava a luz da máquina sobre os corpos e irradiava-a para o fundo sombrio, criando composições quase ectoplasmáticas. A feição espectral também é condizente com a aparição materna, ainda mais inacessível se considerarmos o perfil público dos fotografados de Nadar: como as personalidades francesas, a mãe de Paulo é nada além de efígie, imagem forjada, simulacro, "por semelhança". Essa ideia já se delineava na representação da rapariga alemã, visto que o amante atormentado tentava reconstruí-la mentalmente, "como se decalcasse do original uma cópia fidelíssima de pinacoteca".30 Note-se, no entanto, predominar naquela ocasião o referencial pictórico, reforçado pela alusão a Rubens, ora substituído pelo fotográfico: a primeira é colorida e contemplada à distância, como quadro de museu, enquanto a última é perturbadoramente penumbro-

28. Idem, p. 36.

29. Apud fabris, Annateresa. Da reivindicação de Nadar a Sherrie Levine: autoria e direitos autorais na fotografia, Revista Studium, n. 16, p. 62. Acesso: janeiro de 2005.

30. DUQue, Gonzaga. Op. cit., p. 27.

190 - ARAÚ JO, Gilberto. Em busca da cabeça perdida 
sa e portátil. Aliás, no quesito do convívio interartístico, a tia, sedutora mas intocável/ intocada, fora comparada às "músicas de Meyerbeer e Wagner". ${ }^{1}$

Objetiva e fantasmática, a fotografia de Nadar assume concretude aterradora, quando cotejada ao feitio sinuoso da pintura flamenga ou às notas misteriosas de Wagner. Disso decorre sua força desveladora, aspecto teorizado por Roland Barthes em A câmara clara. O francês opõe, na imagem fotográfica, o studium - o todo captável, aparente e ostensivo - ao punctum, manancial secreto e epifânico sob a superfície do instantâneo. É essa potência que

parte da cena, como uma flecha, e vem me transpassar. Em latim existe uma palavra para designar essa ferida, essa marca feita por um instrumento pontudo; essa palavra me serviria em especial na medida em que remete também à ideia de pontuação e em que as fotos de que falo são, de fato, como que pontuadas, às vezes até mesmo mosqueadas, com esses pontos sensíveis, essas marcas, essas feridas são precisamente pontos. A esse segundo elemento que vem contrariar o studium chamarei então de punctum, pois punctum é também picada, pequeno buraco. ${ }^{32}$

Elo entre imagem e sujeito, o punctum devolve ao observador algo dele que, mesmo involuntariamente, estava nela alocado. Daí os signos do campo semântico da precisão e da dor: flecha, dardo, picada, buraco. A imagem passa a sublinhar ausências, gravadas por Gonzaga Duque em ingredientes pontiagudos, sugestivos tanto do arremate lancinante quanto do inegável conteúdo erótico acendido pelo molde fálico da sabre: "Um fio fosforescente apunhalou a tortura de seu cérebro com a lembrança de antiga coleção fotográfica". ${ }^{33}$ De certo modo, essas fissuras do real estavam pressagiadas no pórtico narrativo, nos stores e cambiantes presentes no quarto.

Golpeado duplamente ao saber que o rosto faltoso pertence à mãe e que dele só restam clones imperfeitos, Paulo converte-se em "símbolo da Insaciedade Humana, o eterno Condenado às torturas do Além". ${ }^{34}$ Não obstante o desfecho generalizante, de

\footnotetext{
31. Idem, p. 32.

32. BARThes, Roland. A câmara clara. 9 ed. Tradução de Julio Castañon Guimarães. Rio de Janeiro: Nova Fronteira, 1984, p. 46.

33. DUQUe, Gonzaga. Op. cit., p. 36.

34. Idem, p. 38 .
} 
inclinação metafísica, "Agonia por semelhança" repertoria pouco antes extenso painel de abjeções orgânicas: à brumosa paisagem boreal sucede uma "charneca ao crepúsculo morrente, sob um céu tetanizado de verão" ${ }^{35}$, onde pululam "paragem negra de hulha", "solo infecto de lodo", "monstro escamado de bostelas pútridas", "escamas viscosas, esverdinhadas e ulcerentas, destilando pus", "carranca feita de um crânio descarnado de gorila", "fibrilhas chagosas de carne nauseabunda", "restos macerados" e "sangue coagulado, de rubro sangue vivo e de excremento". ${ }^{6}$

Conquanto se esforce por exibi-la símbolo da Virtude, Senhora e Eleita, a imagem maternal descamba em simbologia de todo avessa à pureza, no exato momento em que Paulo constata, aterrorizado (daí a trágica rejeição), ser da mãe a fisionomia ausente da compleição utópica. Por sinal, o cortejo repugnante finda em sangue, alusivo à fertilidade maternal esboçada no início do texto. Quase nada resta do branco inaugural, e a atmosfera lodosa de agora embraça-se à capa da brochura verde de Panteu, lida por Paulo na instauração do colapso. A menção ao livro francês não é gratuita: seu autor, Sar Péladan, conhecido no final do século XIx por envolver-se com alquimia, ocultismo, cabala, magia e Rosa-Cruz, dedica nessa obra de 1892 (no original Le panthée) alguns capítulos à maternidade, sempre concebida à luz de conviç̧ões esotéricas:

Il y a dans la mère, une splendeur qui n'appartient pas à la femme, mais sans doute descend du Ciel comme une grâce miraculeuse quando naît lenfant. ${ }^{37}$

Être mère, c’est naître à un état spécial qui n’est plus humain, qui n'est pas encore Le divin, que attendrit comme l'um, éblouissant comme l'autre. ${ }^{38}$

Dessexualizar a figura materna, eis o propósito que une Paulo, Peladan e os higienistas do século XIX, antecipando, ainda que às avessas, aquilo que Freud chamaria de complexo de Édipo, conceito aqui não desenvolvido, pois destoaria o trabalho de seu escopo literário, não psicanalítico. Como a Salomé requerente da cabeça de São João Batista, o

\footnotetext{
35. Idem, p. 37.

36. Idem, pp. 37-38.

37. PÉLADAN, Joséphin. La décadence latine éthopée $x$ Le panthée. Paris: F. Dentu Editeur, Libraire de la Societé de Gens de Lettres, 1892, p. 87.

38. DUQUe, Gonzaga. Op. cit., p. 88.
}

192. ARAÚJO, Gilberto. Em busca da cabeça perdida 
vulto materno assombra o filho, recordando-lhe a impertinência do modelo asséptico e moralista. Ao contrário do Paulo bíblico, que fica cego para voltar a ver, o homônimo de Gonzaga Duque prefere a cegueira edipiana, aqui a serviço da denegação de pulsões matriciais, até que amanhã o rapaz recomece a leitura abandonada sobre a otomana do quarto claro e entre em nova crise rememorativa.

Gilberto Araújo é professor do Programa de Pós-Graduação em Letras Vernáculas da UFRJ, onde também é professor adjunto de Literatura Brasileira. Doutor em Letras Vernáculas (UFRJ), publicou diversos ensaios e palestrou no Brasil e no exterior e, atualmente, é bolsista da Fundação Biblioteca Nacional, onde desenvolve pesquisa sobre a produção verbovisual de Raul Pompeia. Além dos estudos acerca da literatura brasileira sobre o século xIx, desenvolve pesquisa sobre as relações da literatura brasileira e visualidade (com ênfase em Raul Pompeia e escritores simbolistas), bem como os desdobramentos simbólicos da alimentação e da gastronomia na literatura brasileira da Belle Époque. Autor de Literatura brasileira: pontos de fuga (Verve, 2014), Júlio Ribeiro (ABL, 2011), Melhores crônicas de Humberto de Campos (Global, 2009), dentre outros. 